\title{
Teneligliptin in management of type 2 diabetes mellitus
}

This article was published in the following Dove Press journal: Diabetes, Metabolic Syndrome and Obesity:Targets and Therapy 16 August 2016

Number of times this article has been viewed

\author{
Surendra Kumar Sharma' \\ A Panneerselvam² \\ KP Singh ${ }^{3}$ \\ Girish Parmar ${ }^{4}$ \\ Pradeep Gadge \\ Onkar C Swami ${ }^{6}$ \\ 'Diabetes, Thyroid and Endocrine \\ Centre, Galaxy Speciality Centre, \\ Jaipur, ${ }^{2}$ Aruna Diabetes Centre, \\ Chennai, ${ }^{3}$ Fortis Hospital, Sector \\ 62, Phase VIII, Mohali, ${ }^{4}$ Kokilaben \\ Dhirubhai Ambani Hospital, Andheri \\ (W), Mumbai, ${ }^{5} \mathrm{Dr}$ Gadge's Diabetes \\ Care Centre, Mumbai, ${ }^{6}$ Unichem \\ Laboratories Ltd, Jogeshwari (W), \\ Mumbai, India
}

\begin{abstract}
Teneligliptin is a recently developed oral dipeptidyl peptidase 4 inhibitor indicated for the management of type 2 diabetes mellitus (T2DM) in adults along with diet and exercise. Teneligliptin has been recently available in Japan $\left(\right.$ Teneria $\left.^{\circledR}\right)$, Argentina (Teneglucon $\left.{ }^{\circledR}\right)$, and India (Tenepure; Teneza) at relatively affordable price. This is a positive step toward the management of T2DM in developing countries, where the cost of medicine is out-of-pocket expenditure and is a limiting factor for health care. This review evaluates the efficacy and safety of teneligliptin in the management of T2DM. Teneligliptin has been systematically evaluated in T2DM as monotherapy with diet and exercise and in combination with metformin, glimepiride, pioglitazone, and insulin in short-term (12 weeks) and long-term ( 52 weeks) studies. These studies have reported a reduction in $\mathrm{HbA} 1 \mathrm{c}$ of $0.8 \%-0.9 \%$ within 12 weeks of therapy. Two 52-week studies reported sustained improvement in glycemic control with teneligliptin. Teneligliptin has been found to be well tolerated, and the safety profile is similar to other dipeptidyl peptidase 4 inhibitors. Hypoglycemia and constipation are the main adverse events. Teneligliptin can be administered safely to patients with mild, moderate, or severe renal impairment or end-stage renal disease without dose adjustment. Similarly, it can be used in patients with mild-to-moderate hepatic impairment. Teneligliptin is effective and well tolerated and may have an important role in the management of T2DM.
\end{abstract}

Keywords: diabetes mellitus, dipeptidyl peptidase 4 inhibitor, newer DPP-4 inhibitor, teneligliptin, India

\section{Introduction}

Diabetes is a common noncommunicable disease and has reached to epidemic stage in many countries. Globally, 415 million people are living with diabetes and it is a leading cause of death. This number is expected to rise to 642 million by 2040 . A mortality burden of 5 million was noted with diabetes. The People's Republic of China, India, the US, and the Russian Federation reported highest deaths due to diabetes. ${ }^{1}$

Diabetes affects many organs, and complications due to high blood glucose are an important cause of disability, reduced quality of life, and premature death. ${ }^{1}$ In 2015 , globally, $\sim 5$ million people aged between 20 years and 79 years died due to diabetes; this accounts for one death every 6 seconds. ${ }^{1}$

Diabetes is a chronic disease that requires lifelong medical care and attention for multiple risk reduction and treatment approach beyond glycemic control. ${ }^{2}$ Treatment objective must be the prevention of short-term and long-term complications associated with diabetes. ${ }^{3}$ Additionally, patient education and support are important aspects. ${ }^{3}$ This
Correspondence: Onkar C Swami Unichem Laboratories Ltd, Unichem Bhavan, Prabhat Estate, SV Road, Jogeshwari (W), Mumbai 400102, India Email onkar.swami@unichemlabs.com 
will improve patient outcomes. ${ }^{2}$ A multidisciplinary approach is required for the management of diabetes. ${ }^{2,3}$

Considering the huge epidemic of type 2 diabetes mellitus (T2DM), newer therapies that improve efficacy, tolerability, and long-term compliance and prevent complications associated with T2DM are always required and preferred. ${ }^{4}$ Recently, a new and relatively economic dipeptidyl peptidase 4 (DPP-4) inhibitor, teneligliptin, has been made available in some countries such as Japan (Teneria ${ }^{\circledR}$ ), Argentina (Teneglucon ${ }^{\circledR}$ ), and India (Tenepure; Teneza). ${ }^{5-7}$ This review highlights the place of therapy of teneligliptin in the management of T2DM.

\section{The economic costs of T2DM}

There is a substantial economic impact of diabetes on individuals, society, health care system, employer, and even the country in terms of loss of productivity. ${ }^{8}$ Reported evidence suggests that there is a strong and direct economic impact of T2DM on the lives of people in lower income settings. ${ }^{8}$ In developing countries, where health care expenditure is many times out-of-pocket, an economic impact of T2DM is huge and may affect the long-term outcome of T2DM. ${ }^{8}$

There is wide variation in the indirect and direct costs incurred for diabetes in a studied year. In Mexico, direct cost including out-of-pocket expenditures was \$242, while it was reported as $\$ 11,917$ in the $U S{ }^{8}$ Similarly, indirect cost ranged from $\$ 45$ in Pakistan to $\$ 16,914$ in the Bahamas. ${ }^{8}$ It was also reported that in low- and middle-income countries, out-of-pocket expenditure on health care cost has a significant burden. ${ }^{8}$

This highlights that there should be affordable medical treatment available to all. The cost of medicine should not be a barrier for health care. In this scenario, availability of economical DPP-4 inhibitors such as teneligliptin is a positive step.

\section{Management of T2DM}

T2DM is a chronic progressive disease and involves multiple systems. Diet, exercise, education, pharmacotherapy, and blood glucose monitoring are important pillars for the management of T2DM. ${ }^{9}$ Published evidence suggests that even $1 \%$ reduction in $\mathrm{HbA} 1 \mathrm{c}$ reported significant reduction in the risk of long-term complications associated with T2DM (Figure 1). ${ }^{10}$

Various patient and disease factors affect HbA1c targets. Therefore, individualized glycemic goals are always preferred, and tailor-made antidiabetic therapy is recommended in routine clinical practice. ${ }^{9,11}$ Factors determining individual glycemic goal are presented in Table $1 .^{9,11}$ There are various approaches for initiation and titration of antidiabetic therapy. The American Diabetes Association (ADA) position statement of Standards of Medical Care in Diabetes - 2016 has recommended evidence-based antidiabetic therapy (Table 2). ${ }^{12}$

Table I Factors determining individual glycemic goal
Glycemic goal
I. AACE: HbAlc $\leq 6.5 \%$
2. ADA: $\mathrm{HbAlc}<7 \%$
Factors determining $\mathrm{HbAlc}$ goal
I. Age of the patient
2. Hypoglycemia risk
3. Associated comorbidities
4. Duration of disease
5. Life expectancy

Note: Data from previous studies. 911

Abbreviations: AACE, American Association of Clinical Endocrinologists; ADA, American Diabetes Association.

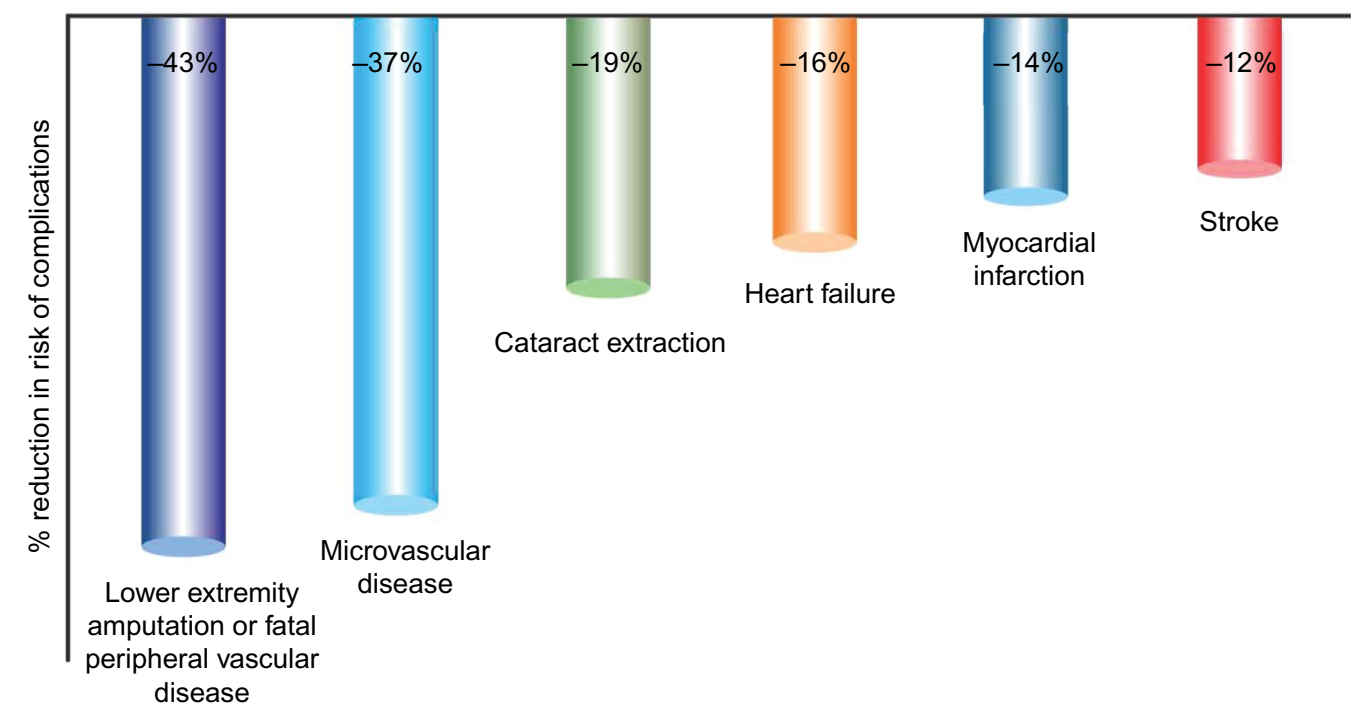

Figure I Reduction in risk of long-term complications associated with $1 \%$ reduction in $\mathrm{HbAlc}$. Note: Data from a previous study..$^{10}$ 
Table 2 ADA recommendations of antihyperglycemic therapy in T2DM

\begin{tabular}{|c|c|c|c|c|c|c|}
\hline \multicolumn{7}{|c|}{ Life style modification: healthy diet, weight control, increased physical activity, diabetes education } \\
\hline Monotherapy & Metformin & & & & & \\
\hline \multicolumn{7}{|c|}{ If $\mathrm{HbAlc}$ target is not achieved after $\sim 3$ months of monotherapy, proceed to two-drug combinations as follows: } \\
\hline Dual therapy & Metformin $+\mathrm{SU}$ & Metformin + TZD & Metformin + DPP-4i & $\begin{array}{l}\text { Metformin }+ \\
\text { SGLT2-i }\end{array}$ & $\begin{array}{l}\text { Metformin + } \\
\text { GLP-IRA }\end{array}$ & $\begin{array}{l}\text { Metformin + basa } \\
\text { insulin }\end{array}$ \\
\hline \multicolumn{7}{|c|}{ If $\mathrm{HbAIc}$ target is not achieved after $\sim 3$ months of dual therapy, proceed to three-drug combinations as follows: } \\
\hline Triple therapy & $\begin{array}{l}\text { Metformin }+ \text { SU + } \\
\text { TZD or DPP4-i or } \\
\text { SGLT2-i or GLP- } \\
\text { IRA or basal insulin }\end{array}$ & $\begin{array}{l}\text { Metformin + TZD } \\
+ \text { SU or DPP4-i or } \\
\text { SGLT2-i or GLP- } \\
\text { IRA or basal insulin }\end{array}$ & $\begin{array}{l}\text { Metformin + DPP-4i } \\
+ \text { SU or TZD or } \\
\text { SGLT2-i or basal } \\
\text { insulin }\end{array}$ & $\begin{array}{l}\text { Metformin }+ \\
\text { SGLT2-i + SU or } \\
\text { TZD or DPP-4 i } \\
\text { or basal insulin }\end{array}$ & $\begin{array}{l}\text { Metformin }+ \\
\text { GLP-IRA }+ \text { SU } \\
\text { or TZD or basal } \\
\text { insulin }\end{array}$ & $\begin{array}{l}\text { Metformin + } \\
\text { basal insulin + } \\
\text { TZD or DPP4-i } \\
\text { or SGLT2-i or } \\
\text { GLP-IRA }\end{array}$ \\
\hline
\end{tabular}

If HbA Ic target is not achieved after $\sim 3$ months of triple therapy, and patient I) on oral combination, move to injectables 2) on GLP-IRA, add basal insulin, or 3) on optimally titrated basal insulin, add GLP-IRA or mealtime insulin. In refractory patients, consider adding TZD or SGLT2-i

Combination

Metformin + basal insulin + mealtime insulin or GLP-I RA

injectable therapy ${ }^{\mathrm{b}}$

Notes: ${ }^{a}$ Consider starting at this stage when HbAlc is $\geq 9 \%$. ${ }^{\circ}$ Consider starting at this stage when blood glucose is $\geq 300-350 \mathrm{mg} / \mathrm{dL}$ and/or $\mathrm{HbAlc}$ is $\geq 10 \%-12 \%$, especially if symptomatic or catabolic features are present, in which case insulin + mealtime is the preferred initial regimen. Basal insulin: NPH, glargine, detemir, degludec. Data from a previous study. ${ }^{12}$

Abbreviations: ADA, American Diabetes Association; DPP-4, dipeptidyl peptidase 4; DPP-4-i, DPP-4 inhibitor; GLP-I-RA, GLP-I receptor agonist; SU, sulfonylurea; SGLT2-i, sodium-glucose cotransporter 2 inhibitor; T2DM, type 2 diabetes mellitus; TZD, thiazolidinedione.

\section{Role of DPP-4 inhibitors in the management of T2DM}

The first DPP-4 inhibitor, sitagliptin, was approved in 2006 for the treatment of T2DM concurrently with lifestyle changes. ${ }^{13}$ As mentioned in Table 2, DPP-4 inhibitors are recommended as monotherapy or in double and triple drug combination with other oral glucose-lowering agents such as metformin, sulfonylureas, thiazolidinediones, or even with insulin. ${ }^{12}$ As a class, DPP-4 inhibitors are considered as a cornerstone in the management of T2DM due to their efficacy, favorable tolerability profile such as low risk of hypoglycemia and weight gain, and compliance due to once-a-day dosage. ${ }^{14}$

Currently, eight DPP-4 inhibitors, namely, alogliptin, anagliptin, gemigliptin, linagliptin, saxagliptin, sitagliptin, teneligliptin, and vildagliptin, are available for the management of T2DM. ${ }^{15}$ All these DPP-4 inhibitors have a similar mechanism of action and safety profile. In spite of their similar mechanism of action, DPP-4 inhibitors differ in some important pharmacokinetic and pharmacodynamic parameters, which may have clinical significance in real-life scenario (Table 3). ${ }^{14}$

Adverse events like immune dysfunction, impaired healing and skin reactions are reported and may be due to

Table 3 Important differences among eight DPP-4 inhibitors

Pharmacokinetic Oral bioavailability, elimination half-life, binding to differences plasma proteins, metabolic pathways, formation of active metabolite(s), main excretion routes, and potential drug-drug interactions

Pharmacodynamic Potency, target selectivity, dosage adjustment for differences renal and liver insufficiency

Note: Data from a previous study. ${ }^{14}$

Abbreviation: DPP-4, dipeptidyl peptidase 4.

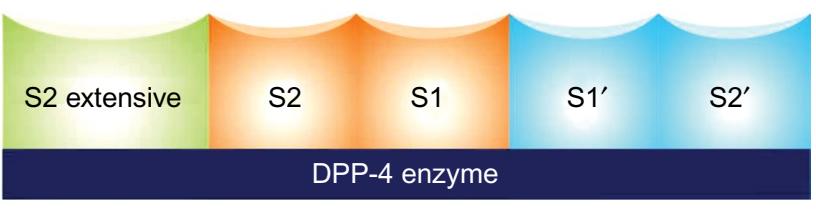

Figure 2 DPP-4 enzyme-binding sites. Note: Data from a previous study. ${ }^{16}$

off-target inhibition of selective DPP-4 enzymes. ${ }^{14}$ However, these toxicities are not clinically significant.

\section{Are all DPP-4 inhibitors same?}

As mentioned earlier, all DPP-4 inhibitors have the same mechanism of action and safety profile, but there are some important differences not only in the pharmacokinetic and pharmacodynamic properties but also in the potency of DPP-4 enzyme inhibition. ${ }^{14}$

Comparative studies have determined binding modes of DPP-4 inhibitors with the active site of DPP-4 enzyme. ${ }^{16,17}$ DPP-4 enzyme has five binding sites (subsites), namely, S1, S2, S1', S2', and S2 extensive (Figure 2). ${ }^{16,17}$ An interaction of DPP-4 inhibitors with S1 and S2 is considered to be the fundamental interaction that is required for DPP-4 inhibition. ${ }^{16}$ Additional interaction with $\mathrm{S}^{\prime}, \mathrm{S} 2^{\prime}$, and $\mathrm{S} 2$ extensive site may further increase the DPP-4 inhibition. ${ }^{16}$ DPP- 4 inhibitors are classified according to their interactions with a DPP-4 enzyme (Table 4). ${ }^{16}$ Classification of DPP-4 inhibitors is based on their selectivity for enzyme and are Class 1 , Class 2 , and Class $3 .^{16}$ Class 1 inhibitors (eg, vildagliptin and saxagliptin) bind with $\mathrm{S} 1$ and $\mathrm{S} 2$ and are considered as fundamental/basic inhibitors. ${ }^{16}$ Class 2 inhibitors (alogliptin and linagliptin) bind with additional sites of $\mathrm{S}^{\prime}{ }^{\prime}$ and $\mathrm{S}^{\prime}$ and may produce more DPP-4 inhibition than Class $1 .{ }^{16}$ Class 3 inhibitors (sitagliptin and 
Table 4 Summary of the interactions of various DPP-4 inhibitors with DPP-4 enzyme

\begin{tabular}{lllll}
\hline Class & $\begin{array}{l}\text { DPP-4 } \\
\text { inhibitors }\end{array}$ & $\begin{array}{l}\text { Binding at } \\
\text { DPP-4 }\end{array}$ & Interaction with DPP-4 at various sites & Details \\
\hline I & $\begin{array}{l}\text { Vildagliptin } \\
\text { and saxagliptin }\end{array}$ & $\begin{array}{l}\mathrm{SI} \text { and S2 } \\
\text { subsites }\end{array}$ & &
\end{tabular}

2

$\begin{array}{ll}\text { Alogliptin and } & \mathrm{SI}, \mathrm{S} 2, \mathrm{SI}^{\prime} \\ \text { linagliptin } & \text { and } \mathrm{S2}^{\prime} \\ & \text { subsites }\end{array}$

3

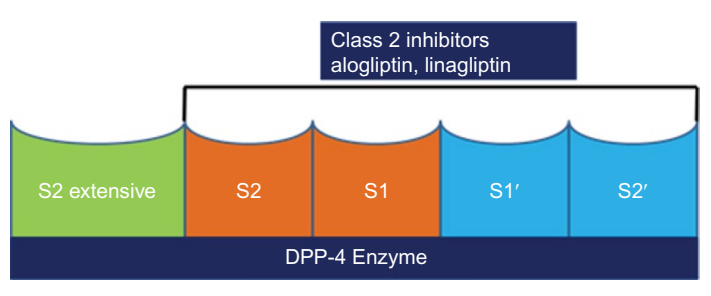

- Additional binding to $\mathrm{SI}^{\prime}$ and $\mathrm{S2}^{\prime}$

- Alogliptin binds to $\mathrm{SI}, \mathrm{S2}$, and $\mathrm{SI}^{\prime}$

- Linagliptin binds to $\mathrm{SI}, \mathrm{S2}, \mathrm{SI}^{\prime}$, and $\mathrm{S2}^{\prime}$

- Linagliptin had eightfold higher activity than alogliptin
3 Sitagliptin and SI, S2, teneligliptin and $\mathrm{S} 2$ extensive subsites

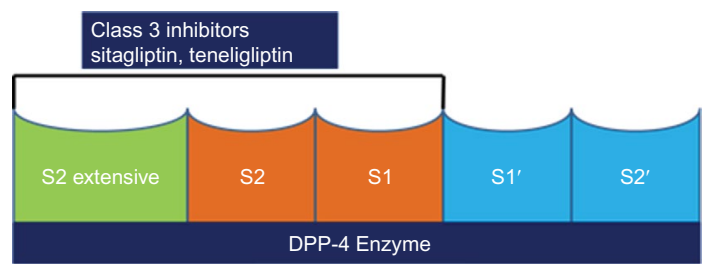

- Binds SI, S2, and S2 extensive

- Teneligliptin has fivefold higher activity than sitagliptin, because of:

- Teneligliptin has favorable (J-shaped) structure leading to small loss of energy during binding with DPP-4

- Teneligliptin forms hydrogen bond with DPP-4

- Teneligliptin has more extensive binding at "S2 extensive" site than sitagliptin

Note: Data from a previous study. ${ }^{16}$

Abbreviation: DPP-4, dipeptidyl peptidase 4.

teneligliptin) bind additional site of $\mathrm{S} 2$ extensive and produce more extensive DPP-4 inhibition. ${ }^{16}$ Teneligliptin, a Class 3 inhibitor, reported fivefold higher activity than sitagliptin. ${ }^{16}$

\section{Teneligliptin}

Teneligliptin is a novel oral DPP-4 inhibitor developed by Mitsubishi Tanabe Pharma Co. and approved in Japan in September 2012 for the management of T2DM. ${ }^{5}$ Currently, teneligliptin is marketed in Japan (Teneria), Argentina (Teneglucon), and India (Tenepure; Teneza) (Table 5) ${ }^{5-7}$ Presently, teneligliptin is registered in South Korea and is in the preregistration phase in Indonesia. Additionally, teneligliptin is in phase II clinical trials in Europe, and phase I clinical trials in the US. ${ }^{18}$ Teneligliptin, which is classified as peptidomimetic, has a unique structure having five consecutive rings. ${ }^{16}$ Due to this unique structure, teneligliptin acts on S2 extensive subsite of DPP-4; this interaction enhances its potency and selectivity. ${ }^{5}$

\section{Pharmacokinetics of teneligliptin}

Reported evidence suggests that with teneligliptin $20 \mathrm{mg}$ therapy, $T_{\max }$ was 1 hour and $t_{1 / 2}$ was 18.9 hours. Maximum $(89.7 \%)$ inhibition in plasma DPP-4 activity was noted
Table 5 Approval status of teneligliptin

\begin{tabular}{lll}
\hline Phase of development & Indication & Country \\
\hline Marketed & T2DM & Japan \\
Marketed & T2DM & Argentina \\
Marketed & T2DM & India \\
\hline
\end{tabular}

Note: Teneligliptin is marketed in Japan, ${ }^{5}$ Argentina, ${ }^{6}$ and India. ${ }^{7}$ Abbreviation: T2DM, type 2 diabetes mellitus.

within 2 hours and maintained $>60 \%$ at 24 hours. Compared to placebo, active plasma GLP-1 concentration was higher throughout the day and even at 24 hours after administration of teneligliptin $20 \mathrm{mg}$. Metabolism of teneligliptin was majorly mediated through CYP3A4, a cytochrome P450 isozyme, and flavin-containing monooxygenases (FMO1 and FMO3). ${ }^{5}$

A weak inhibitory activity of teneligliptin on CYP2D6, CYP3A4, and FMO was noted, while there was no inhibitory activity on CYP1A2, CYP2A6, CYP2B6, CYP2C8, CYP2C $8 / 9$, CYP2C19, and CYP2E1. There was no induction of expression of CYP1A2 or CYP3A4. ${ }^{5}$

Reported evidence suggests that teneligliptin is metabolized and eliminated via both renal and hepatic routes. Approximately $34 \%$ of teneligliptin is excreted unchanged via the renal route, while $66 \%$ is metabolized and eliminated via the hepatic and renal routes. ${ }^{5}$ 


\section{Teneligliptin in renal impairment}

Halabi et al studied the pharmacokinetics of a single oral dose of teneligliptin $20 \mathrm{mg}$, in subjects with renal impairment and end-stage renal disease (ESRD). Subjects participating in this study were allocated to six groups based on their renal function. Out of these six groups, four groups comprised subjects having mild, moderate, and severe renal impairment and ESRD, respectively, while two groups were having healthy subjects with a normal renal function. Eight subjects were included in each group to have at least six evaluable subjects in each group at the end. This study revealed that teneligliptin $20 \mathrm{mg}$ single oral dose had no effect on maximum plasma concentration $\left(C_{\max }\right)$ in patients with mild, moderate, and severe renal impairment. There was an increase in $\mathrm{AUC}_{0-\infty}$ in subjects with renal impairment across the group compared to healthy subjects; however, this was unrelated to the degree of renal impairment. Teneligliptin was well tolerated by subjects with renal impairment or ESRD. Dialysis was not expected to affect the efficacy or safety of teneligliptin. This study concluded that dose adjustment may not be needed when teneligliptin is administered to subjects with mild, moderate, or severe renal impairment or ESRD. ${ }^{19}$

The efficacy and safety of teneligliptin in diabetic ESRD patients undergoing hemodialysis were studied through a bicenter, prospective, nonrandomized study. A total of 45 patients were enrolled in this study, which included 16 patients enrolled in the teneligliptin group ( 7 therapy-naïve and 9 switched from other medications) and 29 in the control group. Fourteen patients in the teneligliptin group (7 each as therapy-naïve and switched from other medications) and 29 in the control group completed 28 -week study period. At 4 weeks, $36.7 \mathrm{mg} / \mathrm{dL}$ reduction in blood glucose was noted in the teneligliptin group $(P<0.05)$. More prominent reduction of $3.1 \%$ in glycated albumin was noted in the teneligliptin group than the control group $(P<0.05)$. Similarly, more reduction in $\mathrm{HbA1c}$ (difference $-0.57 \% ; P=0.057$ ) was noted in the teneligliptin group compared to the control group. Reduction in these variables was also noted in patients who were switched to teneligliptin from voglibose $0.2 \mathrm{mg}$ three times in a day (tid) or vildagliptin $50 \mathrm{mg}$ once per day (qd). Interestingly, this study reported that teneligliptin $20 \mathrm{mg}$ daily was more potent than voglibose $0.2 \mathrm{mg}$ tid or vildagliptin $50 \mathrm{mg}$ qd. However, a small number of patients were switched to teneligliptin from voglibose or vildagliptin, and no statistical analysis was performed. Teneligliptin was well tolerated without any episodes of hypoglycemia during the study period. The study concluded that in diabetic patients with ESRD, teneligliptin significantly improved glycemic control and was well tolerated. Teneligliptin appeared to be more potent than voglibose or vildagliptin based on its glucose-lowering effects. ${ }^{20}$

The efficacy and safety of linagliptin and teneligliptin on glycemic control in T2DM with chronic kidney disease (CKD) were assessed in a pilot study through continuous glucose monitoring. This was a randomized crossover study including 13 patients with T2DM with CKD having $\mathrm{HbA} 1 \mathrm{c}<9 \%$ and estimated glomerular filtration rate $<60 \mathrm{~mL} / \mathrm{min} / 1.73 \mathrm{~m}^{2}$. There were two groups receiving either teneligliptin or linagliptin for 6 days from hospital day 5 and followed by crossover to linagliptin or teneligliptin on hospital day 11 for the next 6 days. The primary outcome of changes in the mean amplitude of glucose excursions was similar in both the groups. Equivalent effects on 24-hour mean sensor glucose levels and area under the curve for sensor glucose levels were noted for both the groups. A similar incidence of hypoglycemia was noted. The study concluded that in patients with T2DM with CKD, teneligliptin and linagliptin have comparable effects on blood glucose and a similar safety profile. ${ }^{21}$

\section{Teneligliptin in the management of T2DM: an evolving landscape Effects of teneligliptin on 24-hour blood glucose control}

A 4-week, randomized, double-blind, placebo-controlled, parallel-group study was conducted to analyze the pharmacokinetic and pharmacodynamic characteristics, effects on blood glucose control over 24 hours, and safety of once-daily teneligliptin in patients with T2DM inadequately controlled with diet and exercise. A total of 99 subjects, which included 32,34 , and 33 subjects in a placebo, teneligliptin $10 \mathrm{mg}$ group, and teneligliptin $20 \mathrm{mg}$ group, respectively, were randomized and analyzed. Plasma concentration of teneligliptin was maintained for 24 hours; similarly $>50 \%$ inhibition of DPP-4 was noted at 24 hours of administration. Compared to the placebo group, significantly lower 2-hour postprandial glucose (2-hour PPG), 24-hour mean glucose, and fasting plasma glucose (FPG) were noted in teneligliptin $10 / 20 \mathrm{mg}$ treated groups. Teneligliptin $10 \mathrm{mg}$ reported more reduction in 2-hour PPG after each meal compared to placebo. Compared to placebo, a mean difference of $-50.7 \mathrm{mg} / \mathrm{dL}$, $-34.8 \mathrm{mg} / \mathrm{dL}$, and $-37.5 \mathrm{mg} / \mathrm{dL}$ was noted $(P<0.001$ for all $)$ in 2-hour PPG after breakfast, lunch, and dinner, respectively, in teneligliptin $10 \mathrm{mg}$ group. Similarly, mean difference in reduction of 2-hour PPG after breakfast, lunch, and dinner 
was $-38.1 \mathrm{mg} / \mathrm{dL}(P<0.001),-28.6 \mathrm{mg} / \mathrm{dL}(P<0.01)$, and $-36.1 \mathrm{mg} / \mathrm{dL}(P<0.001)$, respectively, with teneligliptin $20 \mathrm{mg}$ compared to placebo. Postprandial plasma active glucagon-like peptide-1 concentrations were also increased with teneligliptin 10/20 mg compared to placebo. A similar incidence of adverse events (AEs) was noted in all groups with no incidence of serious AE including hypoglycemia. ${ }^{22}$

\section{Role of teneligliptin in patients with T2DM inadequately controlled with diet and exercise}

Kadowaki et al evaluated the efficacy, safety, and doseresponse relationship of teneligliptin in Japanese patients with T2DM and inadequately controlled with diet and exercise through a randomized, double-blind, placebo-controlled, parallel-group study for 12 weeks. A total of 324 Japanese T2DM patients with age 20-75 years, HbA1c 6.8\%-9.8\%, and not taking any oral antihyperglycemic agent for $\geq 8$ weeks were randomized to receive teneligliptin $10 \mathrm{mg}(\mathrm{n}=84), 20 \mathrm{mg}$ $(\mathrm{n}=79), 40 \mathrm{mg}(\mathrm{n}=81)$, and placebo $(\mathrm{n}=80)$ once daily for 12 weeks. Significantly greater reductions in $\mathrm{HbAlc}$ and FPG were reported in all teneligliptin groups compared to placebo group. AEs were similar in all groups. There was no significant difference in the incidence of hypoglycemia among the four groups. ${ }^{23}$ Thus, in patients with T2DM inadequately controlled with diet and exercise, treatment with teneligliptin reported a significant and clinically important reduction in glycemic parameters.

\section{Addition of teneligliptin in patients with T2DM not controlled with metformin therapy}

Efficacy and safety of the addition of teneligliptin in inadequately controlled T2DM patients with metformin monotherapy were evaluated in a randomized, double-blind, placebo-controlled, parallel-group, Phase III study. A total of 204 patients with T2DM with inadequate glycemic control (HbA1c 7.0\%-10.0\%) and receiving stable-dose metformin monotherapy $(\geq 1,000 \mathrm{mg} / \mathrm{d})$ for at least 8 weeks received teneligliptin $20 \mathrm{mg}$ once daily or a placebo once daily for 16 weeks. All patients received background therapy of metformin. At the end of 16 weeks, the difference in HbA1c and FPG levels between teneligliptin and placebo groups was $-0.78 \%$ and $-22.42 \mathrm{mg} / \mathrm{dL}$, respectively. Significantly higher percentage of patients achieved ADA goal (HbA1c $<7 \%$ ) in teneligliptin plus metformin group than placebo plus metformin group (64.71\% vs $13.24 \%$, respectively;
$P<0.001)$. Greater increases in $\beta$-cell function (HOMA- $\beta$; $P=0.0008$ ) and improvement in insulin resistance (HOMAIR; $P=0.1754$ ) were noted in teneligliptin plus metformin group than placebo plus metformin group. A similar incidence of AE was noted in both the groups. Thus, the addition of teneligliptin to metformin treatment was effective in controlling blood glucose and well tolerated in patients with T2DM. ${ }^{24}$

\section{Teneligliptin added to glimepiride in patients with T2DM}

A multicentric, double-blind, placebo-controlled, parallelgroup, Phase III, randomized control trial was conducted to evaluate the efficacy and safety of teneligliptin in combination with glimepiride. A total of 194 Japanese patients with T2DM receiving stable glimepiride ( $1-4 \mathrm{mg} / \mathrm{d}$ ) monotherapy for $\geq 8$ weeks and reporting inadequate glycemic control (HbA1c $7.3 \%-10.3 \%$ ) were randomized to receive teneligliptin $20 \mathrm{mg}$ or placebo once daily in addition to stable glimepiride therapy for 12 weeks. After 12 weeks of the randomized period, all patients followed an open-label period of 40 weeks. During open-label period, all patients received teneligliptin and glimepiride therapy (teneligliptin to teneligliptin and placebo to teneligliptin). At the end of 12 weeks, teneligliptin group reported $0.7 \%$ mean reduction in $\mathrm{HbA} 1 \mathrm{c}$ and difference between placebo group was $1 \%(P<0.001)$. Similarly, mean reduction in FPG and PPG was $17.4 \mathrm{mg} / \mathrm{dL}$ and $43.1 \mathrm{mg} / \mathrm{dL}$, respectively, in the teneligliptin group. The mean difference of FPG and PPG between teneligliptin and placebo groups was $27.1 \mathrm{mg} / \mathrm{dL}(P<0.001)$ and $49.1 \mathrm{mg} / \mathrm{dL}$ $(P<0.001)$, respectively, at the end of 12 weeks. The reduction in $\mathrm{HbA1c}$ was maintained for 52 weeks, and $\mathrm{HbA1c}$ was significantly lower at 52 weeks compared to baseline in both the groups $(P<0.001$ both groups). The mean reduction in $\mathrm{HbA} 1 \mathrm{c}$ at 52 weeks was $0.6 \%$ and $0.9 \%$ in "teneligliptin to teneligliptin" group and "placebo to teneligliptin" group, respectively. Significant improvement in proinsulin/insulin ratio, HOMA- $\beta$, and postprandial glucagon was also noted in the teneligliptin group compared with the placebo group. The incidence of AEs/adverse drug reactions (ADRs) including hypoglycemia with teneligliptin was similar to placebo during the randomized period. Two patients $(2.1 \% ; 0.091$ events/patient-years) in the teneligliptin group and three patients $(3.1 \% ; 0.226$ events/patient-years) in the placebo group reported hypoglycemic symptoms. A similar trend of AEs/ADRs was noted in the open-label period. Only $0.5-0.7 \mathrm{~kg}$ increase in body weight was noted over the 52 -week period. In patients with inadequate glycemic control 
with glimepiride monotherapy, an addition of teneligliptin improved glycemic control, which was sustained for 52 weeks. Teneligliptin therapy was well tolerated. ${ }^{25}$

\section{Teneligliptin added to pioglitazone in patients with T2DM}

Kadowaki et al evaluated the efficacy and safety of teneligliptin added to pioglitazone in patients with T2DM. Two hundred and four patients with T2DM receiving pioglitazone $(15 \mathrm{mg} / \mathrm{d}$ or $30 \mathrm{mg} / \mathrm{d})$ monotherapy for at least 12 weeks and reporting inadequate glycemic control (HbA1c 6.8\%-10.3\%) were randomized to receive teneligliptin $20 \mathrm{mg}$ or a placebo through a multicenter, randomized, double-blind, placebocontrolled, parallel-group, Phase III clinical trial. All patients were continued on a stable dose of pioglitazone in addition to teneligliptin or a placebo. After 12 weeks of the doubleblind period, all patients continued a 40 -week open-label period during which they received teneligliptin $20 \mathrm{mg}$ or $40 \mathrm{mg}$. At 12 weeks, teneligliptin reported a significant reduction in $\mathrm{HbA} 1 \mathrm{c}$ of $0.9 \%$ compared to placebo of $0.2 \%$ $(P<0.001)$. The trend of reduction in $\mathrm{HbA} 1 \mathrm{c}$ continued further for 52 weeks. Patients who were receiving teneligliptin during a double-blind period and who further continued on teneligliptin $(\mathrm{T} / \mathrm{T})$ during an open-label period reported a reduction in $\mathrm{HbA} 1 \mathrm{c}$ of $0.9 \%$ at 52 weeks. Patients who were receiving placebo during a double-blind period and who further continued on teneligliptin $(\mathrm{P} / \mathrm{T})$ during an open-label period reported reduction in $\mathrm{HbA} 1 \mathrm{c}$ of $0.7 \%$ at 52 weeks. Teneligliptin reported more reduction in FPG compared to placebo $(P<0.001)$ at 12 weeks, and this trend continued for 52 weeks. Slightly higher incidences of AE/ADRs were noted in teneligliptin group compared to placebo group at week 12 . Gastrointestinal disorders and skin disorders were commonly reported AEs. Two patients (1.9\%) reported hypoglycemia; however, all episodes of hypoglycemia were mild in severity. Incidences of peripheral edema were low in both the groups, and a slight increase in body weight was noted in both the groups. Thus, improvement in glycemic control was noted with addition of teneligliptin in patients with T2DM with inadequate glycemic control with pioglitazone. ${ }^{26}$

\section{Teneligliptin added to insulin therapy in patients with T2DM}

Efficacy of teneligliptin on glucose fluctuations in patients with T2DM was analyzed in a prospective, nonblinded, pilot study involving 26 patients. These patients were treated with diet and insulin therapy with or without other antidiabetic drugs for steady glycemic control in hospitalized setting.
Continuous glucose monitoring was done successively for 7 days. For the first 3 days (days 1-3), patients received insulin with or without other antidiabetic drugs, and for the next 4 days (days 4-7), teneligliptin $20 \mathrm{mg}$ once daily was added to existing therapy. Insulin dose was kept constant throughout the study period. Significant improvement in various glycemic parameters, such as 24-hour mean glucose levels, a proportion of time in normoglycemia, mean amplitude of glycemic excursions, and total area under the curve within 2 hours after each meal, was noted with the addition of teneligliptin. No significant increase in the proportion of time in hypoglycemia and high-sensitivity C-reactive protein levels was noted with the addition of teneligliptin. This study concluded that in patients with T2DM receiving insulin therapy, with or without other antidiabetic agents, the addition of teneligliptin reported significant improvement in diurnal glycemic control and significant reductions in glucose fluctuations in 24-hour periods without increasing the risk of hypoglycemia. ${ }^{27}$

\section{Tolerability of teneligliptin}

As mentioned earlier, teneligliptin was well tolerated in various clinical trials. ${ }^{22-27}$ Data from 1,183 patients reported that $118(10 \%)$ patients experienced AEs, and the most common AEs were hypoglycemia (3\%) and constipation $(0.9 \%)$. Hypoglycemia can occur when other antidiabetic drugs are coadministered..$^{5}$ Intestinal obstruction may occur with teneligliptin and must be administered cautiously in patients with a history of intestinal obstruction or surgery. ${ }^{5}$ This may be because of reduced gastrointestinal motility due to enhanced activity of incretins. Cases of intestinal obstruction were also reported with sitagliptin, vildagliptin, exenatide, and liraglutide. ${ }^{28}$

QT/QTc evaluation was studied for teneligliptin, this may be as a part of regular drug development program. ${ }^{5,29,30}$ Reported evidence suggests that no QT prolongations were noted with teneligliptin $40 \mathrm{mg}$ daily dose. Nevertheless, mild and transient QTc prolongation can be seen at a supraclinical dose of $160 \mathrm{mg}$ /day given for a prolonged period. 5,28 Therefore, caution is exercised if the drug needs to be used for a longer period of time in patients who are prone or have comorbid arrhythmia/ischemic heart disease and along with medications known for QT prolongation. ${ }^{5,31}$

Cardioprotective effects of teneligliptin were studied in a small group $(n=29)$ of patients with T2DM with a high risk of chronic heart failure. Treatment with teneligliptin for 3 months reported improvements in left ventricular systolic and diastolic function, endothelial function, and an increase 
in circulating adiponectin levels. ${ }^{32}$ This evidence supports cardioprotective effects of teneligliptin.

\section{Summary and expert opinion}

Globally, prevalence of diabetes has reached an alarming stage with 415 million patients. ${ }^{1}$ This has a huge burden on public health system, and prompt intervention is required to reduce various short-term and long-term complications associated with diabetes. In this situation, the addition of newer and effective medicines is always welcomed.

Teneligliptin is a novel DPP-4 inhibitor developed in Japan and recently available in some countries and presently under development in many countries. ${ }^{5-7,18}$ Teneligliptin has a unique structure and binds to S1, S2, and S2 extensive subsite of DPP-4 enzyme leading to enhanced potency and selectivity. ${ }^{16,17}$ Once-a-day administration with maximum inhibition of DPP-4 enzyme within 2 hours and $>50 \%$ inhibition has been noted at 24 hours; no drug-drug interaction and elimination by renal and hepatic route are some of the important clinically significant properties of teneligliptin. ${ }^{5,22}$

Teneligliptin was systematically studied in various patient profiles of T2DM as monotherapy and in combination with metformin, glimepiride, pioglitazone, and insulin..$^{22-27}$ These studies included short-term studies for 12 weeks and longterm studies up to 52 weeks. These studies have reported a significant and clinically meaningful reduction of blood glucose with a reduction of $\mathrm{HbA} 1 \mathrm{c}$ of $0.8 \%-0.9 \%$ in 12 weeks, which was maintained up to 52 weeks of teneligliptin therapy (Table 6). The landscape of these studies has also pointed out that teneligliptin can be safely used as monotherapy and a part of dual therapy. ${ }^{22-27}$

Additionally, there are some signals of possible pleiotropic benefits of teneligliptin in terms of improvement in vascular endothelial function, body weight, and lipid levels. ${ }^{33}$ However, this needs to be confirmed in a well-designed

Table 6 Summary of some important teneligliptin studies

\begin{tabular}{|c|c|c|c|c|}
\hline Study & Treatment arm & Design and duration (weeks) & $\begin{array}{l}\text { Sample } \\
\text { size }\end{array}$ & Mean change in HbAlc (\%) \\
\hline \multicolumn{5}{|c|}{ Patients with T2DM inadequately controlled with diet and exercise } \\
\hline $\begin{array}{l}\text { Kadowaki } \\
\text { and } \\
\text { Kondo }{ }^{23}\end{array}$ & $\begin{array}{l}\text { Teneligliptin } 10 \mathrm{mg} \text { OD } \\
\text { Teneligliptin } 20 \mathrm{mg} \text { OD } \\
\text { Teneligliptin } 40 \mathrm{mg} \text { OD } \\
\text { Placebo OD }\end{array}$ & DB, PL-controlled, MC, PG, RCT, I 2 weeks & 324 & $\begin{array}{l}\text { Teneligliptin } 10 \mathrm{mg}:-0.8 \%^{*} \\
\text { Teneligliptin } 20 \mathrm{mg}:-0.8 \%^{*} \\
\text { Teneligliptin } 40 \mathrm{mg}:-0.9 \%^{*} \\
\text { Placebo: } 0.1 \%\end{array}$ \\
\hline \multicolumn{5}{|c|}{ Patients with T2DM inadequately controlled with metformin } \\
\hline $\begin{array}{l}\text { Kim } \\
\text { et } \mathrm{a}^{24}\end{array}$ & $\begin{array}{l}\text { Metformin }{ }^{\mathrm{a}}+\text { teneligliptin } \\
20 \mathrm{mg} \\
\text { Metformin }\end{array}$ & $\begin{array}{l}\text { DB, PL-controlled, MC, PG, Phase III, RCT, } \\
16 \text { weeks }\end{array}$ & 204 & $\begin{array}{l}\text { Metformin + teneligliptin } 20 \mathrm{mg}:-0.87 \% * * \\
\text { Metformin + placebo: }-0.06 \%\end{array}$ \\
\hline \multicolumn{5}{|c|}{ Patients with T2DM inadequately controlled with glimepiride } \\
\hline \multirow[t]{2}{*}{$\begin{array}{l}\text { Kadowaki } \\
\text { and } \\
\text { Kondo }^{25}\end{array}$} & $\begin{array}{l}\text { Glimepiride }^{\mathrm{b}}+ \\
\text { teneligliptin } 20 \mathrm{mg}\end{array}$ & $\begin{array}{l}\text { DB, PL-controlled, MC, PG, Phase III, RCT, } \\
\text { I } 2 \text { weeks, followed by } 40 \text { weeks open-label } \\
\text { extension: }\end{array}$ & 194 & $\begin{array}{l}\text { At } 12 \text { weeks: } \\
\text { Glimepiride + teneligliptin } 20 \mathrm{mg}:-0.7 \% \\
\text { Glimepiride + placebo: } 0.3 \%\end{array}$ \\
\hline & Glimepiride $^{\mathrm{b}}+$ placebo & $\begin{array}{l}\text { Glimepiride }+ \text { teneligliptin } \rightarrow \text { glimepiride }+ \\
\text { teneligliptin } 20 \mathrm{mg}^{\mathrm{d}}(\mathrm{T} / \mathrm{T}) \\
\text { Glimepiride }+ \text { placebo } \rightarrow \text { glimepiride }+ \\
\text { teneligliptin } 20 \mathrm{mg}^{\mathrm{d}}(\mathrm{P} / \mathrm{T})\end{array}$ & & $\begin{array}{l}\text { At } 52 \text { weeks: } \\
\text { Glimepiride + teneligliptin } 20 \mathrm{mg}(\mathrm{T} / \mathrm{T}) \text { : } \\
-0.6 \% * * * \\
\text { Glimepiride + teneligliptin } 20 \mathrm{mg}(\mathrm{P} / \mathrm{T}) \text { : } \\
-0.9 \% * * *\end{array}$ \\
\hline
\end{tabular}

Patients with T2DM inadequately controlled with pioglitazone

$\begin{array}{lll}\begin{array}{l}\text { Kadowaki } \\ \text { and }\end{array} & \text { Pioglitazone }^{c}+ & \text { DB, PL-controlled, MC, PG, Phase III, RCT, } \\ \text { Kondo }^{26} & \text { teneligliptin } 20 \mathrm{mg} & 12 \text { weeks, followed by } 40 \text { weeks open-label } \\ & & \begin{array}{l}\text { extension: } \\ \text { Pioglitazone }\end{array} \\ & & \begin{array}{l}\text { Pioglitazone }+ \text { teneligliptin } \rightarrow \text { pioglitazone }+ \\ \text { teneligliptin } 20 \mathrm{mg}^{\mathrm{d}}(\mathrm{T} / \mathrm{T})\end{array} \\ & & \begin{array}{l}\text { Pioglitazone }+ \text { placebo }^{\mathrm{d}} \rightarrow \text { pioglitazone }+ \\ \text { teneligliptin } 20 \mathrm{mg}^{\mathrm{d}}(\mathrm{P} / \mathrm{T})\end{array}\end{array}$

204

At 12 weeks:

Pioglitazone + teneligliptin $20 \mathrm{mg}:-0.9 \% *$

Pioglitazone + placebo: $-0.2 \%$

At 52 weeks:

Pioglitazone + teneligliptin $20 \mathrm{mg}(\mathrm{T} / \mathrm{T})$ :

$-0.9 \% * * *$

Pioglitazone + teneligliptin $20 \mathrm{mg}(\mathrm{P} / \mathrm{T}):-0.7 \%$ ****

Notes: ${ }^{2}$ Metformin dosage: $\geq 1,000 \mathrm{mg} / \mathrm{d}$. ${ }^{\mathrm{b}} \mathrm{Glimepiride}$ dosage: $\mathrm{I}-4 \mathrm{mg} / \mathrm{d}$. cPioglitazone dosage: $15 \mathrm{mg} / \mathrm{d}$ or $30 \mathrm{mg} / \mathrm{d}$. d $\mathrm{dptitrated}$ to $40 \mathrm{mg}$ if required. T/T, patients who were receiving teneligliptin during a double-blind period and who further continued on teneligliptin during an open-label period; $P / T$, patients who were receiving placebo during a double-blind period and who further continued on teneligliptin during an open-label period. $* P<0.00$ I versus placebo; $* * P<0.000$ I versus baseline; $* * * P<0.00 I$ versus baseline. Data from previous studies. ${ }^{23-26}$

Abbreviations: AC, active controlled; DB, double blind; DD, double dummy; MC, multicentric; NB, nonblind; OD, once daily; PG, parallel group; PL, placebo; RCT, randomized controlled trial; T2DM, type 2 diabetes mellitus. 
systematic study. This drug is under development in the US and the UK, and it may be available in these countries in near future. ${ }^{18}$

Teneligliptin reported favorable tolerability with few AEs and is weight neutral. No dose adjustment is required in patients with any degree of renal impairment or ESRD and even in mild-to-moderate hepatic impairment. ${ }^{19,20}$ These are some unique and useful properties of teneligliptin.

Presently, no direct comparative study of teneligliptin with another DPP-4 inhibitor is reported; therefore, it is difficult to establish superiority or noninferiority of teneligliptin vis-a-vis with other DPP-4 inhibitors. Nevertheless, it is a welcome addition to the armamentarium of antidiabetic drugs available at a relatively affordable price. A systematic costeffective analysis is required to analyze its economic benefits versus other available antidiabetic therapies.

This drug is recently approved, and therefore, long-term safety studies including cardiovascular safety studies are still awaited and required. However, current data of teneligliptin do not point any signal for serious adverse effect. ${ }^{31,32}$ Current evidence from short-term and small sample size studies supported cardioprotective effects of teneligliptin, which needs to be confirmed in the large randomized long duration study. The majority of studies involved Japanese and Korean (Asian) patients of T2DM, and clinical evidence in another population is missing and required. A properly designed, large, global, long-term safety study of teneligliptin is required.

\section{Conclusion}

Teneligliptin is a newer DPP-4 inhibitor in the management of T2DM. It provides clinically significant glycemic control within 12 weeks of therapy, which was maintained up to 52 weeks of therapy with favorable tolerability. It is useful as monotherapy and in combination with other antidiabetic drugs. It can be used in T2DM patients with renal impairment and mild-to-moderate hepatic impairment and thus has a unique place in therapy.

\section{Disclosure}

Dr Onkar C Swami is a full-time employee of Unichem Laboratories Limited, which actively markets teneligliptin. The other authors report no conflicts of interest in this work.

\section{References}

1. IDF. IDF Diabetes Atlas, 7th Edn. Brussels, Belgium: International Diabetes Federation; 2015.

2. American Diabetes Association. Strategies for improving care. Diabetes Care. 2016;39(suppl 1):S6-S12.

3. American Diabetes Association. Foundations of care and comprehensive medical evaluation. Diabetes Care. 2016;39(suppl 1):S23-S35.
4. Majumdar SK, Inzucchi SE. Investigational anti-hyperglycemic agents: the future of type 2 diabetes therapy? Endocrine. 2013;44(1): 47-58.

5. Kishimoto M. Teneligliptin: a DPP-4 inhibitor for the treatment of type 2 diabetes. Diabetes Metab Syndr Obes. 2013;6:187-195.

6. Scott LJ. Teneligliptin: a review in type 2 diabetes. Clin Drug Investig. 2015;35(11):765-772.

7. https://aiocdawacs.com [homepage on the Internet]. Teneligliptin Data Feb MAT 2016. Data Source from AIOCD-AWACS. Available from: https://aiocdawacs.com/Default.aspx. Accessed June 8, 2016.

8. Seuring T, Archangelidi O, Suhrcke M. The economic costs of type 2 diabetes: a global systematic review. Pharmacoeconomics. 2015; 33(8):811-831.

9. Handelsman Y, Bloomgarden ZT, Grunberger G, et al. American Association of Clinical Endocrinologists and American College of Endocrinology - clinical practice guidelines for developing a diabetes mellitus comprehensive care plan - 2015. Endocr Pract. 2015;21(suppl 1): $1-87$.

10. Stratton IM, Adler AI, Neil HA, et al. Association of glycaemia with macrovascular and microvascular complications of type 2 diabetes (UKPDS 35): prospective observational study. BMJ. 2000;321:405-412.

11. Inzucchi SE, Bergenstal RM, Buse JB, et al; American Diabetes Association (ADA); European Association for the Study of Diabetes (EASD). Management of hyperglycemia in type 2 diabetes: a patient-centered approach: position statement of the American Diabetes Association (ADA) and the European Association for the Study of Diabetes (EASD). Diabetes Care. 2012;35(6):1364-1379.

12. American Diabetes Association. Approaches to glycemic treatment. Diabetes Care. 2016;39(suppl 1):S52-S59.

13. Dror Dicker. DPP-4 inhibitors impact on glycemic control and cardiovascular risk factors. Diabetes Care. 2011;34(2):S276-S278.

14. Chen XW, He ZX, Zhou ZW, et al. Clinical pharmacology of dipeptidyl peptidase 4 inhibitors indicated for the treatment of type 2 diabetes mellitus. Clin Exp Pharmacol Physiol. 2015;42(10):999-1024.

15. Kushwaha RN, Haq W, Katti SB. Discovery of 17 gliptins in 17-years of research for the treatment of type 2 diabetes: a synthetic overview. Chem Biol Interface. 2014;4(3):137-162.

16. Nabeno M, Akahoshi F, Kishida H, et al. A comparative study of the binding modes of recently launched dipeptidyl peptidase IV inhibitors in the active site. Biochem Biophys Res Commun. 2013;434(2):191-196.

17. Yoshida T, Akahoshi F, Sakashita H, et al. Discovery and preclinical profile of teneligliptin (3-[(2S,4S)-4-[4-(3-methyl-1-phenyl-1H-pyrazol5-yl)piperazin-1-yl]pyrrolidin-2-ylcarbonyl]thiazolidine): a highly potent, selective, long-lasting and orally active dipeptidyl peptidase IV inhibitor for the treatment of type 2 diabetes. Bioorg Med Chem. 2012;20(19):5705-5719.

18. Adis R \& D Insight. Teneligliptin. Cham: Springer International Publishing AG; 2015.

19. Halabi A, Maatouk H, Siegler KE, Faisst N, Lufft V, Klause N. Pharmacokinetics of teneligliptin in subjects with renal impairment. Clin Pharmacol Drug Dev. 2013;2(3):246-254.

20. Otsuki H, Kosaka T, Nakamura K, Shimomura F, Kuwahara Y, Tsukamoto T. Safety and efficacy of teneligliptin: a novel DPP-4 inhibitor for hemodialysis patients with type 2 diabetes. Int Urol Nephrol. 2014;46(2):427-432.

21. Tanaka K, Okada Y, Mori H, et al. Efficacy of linagliptin and teneligliptin for glycemic control in type 2 diabetic patients with chronic kidney disease: assessment by continuous glucose monitoring; a pilot study. Diabetol Int. 2016:1-7. Available from: http://link.springer.com/ article/10.1007\%2Fs13340-016-0258-y. Accessed June 8, 2016.

22. Eto T, Inoue S, Kadowaki T. Effects of once-daily teneligliptin on 24-h blood glucose control and safety in Japanese patients with type 2 diabetes mellitus: a 4-week, randomized, double-blind, placebo-controlled trial. Diabetes Obes Metab. 2012;14(11):1040-1046.

23. Kadowaki T, Kondo K. Efficacy, safety and dose-response relationship of teneligliptin, a dipeptidyl peptidase-4 inhibitor, in Japanese patients with type 2 diabetes mellitus. Diabetes Obes Metab. 2013;15(9): 810-818. 
24. Kim MK, Rhee EJ, Han KA, et al. Efficacy and safety of teneligliptin, a dipeptidyl peptidase-4 inhibitor, combined with metformin in Korean patients with type 2 diabetes mellitus: a 16-week, randomized, doubleblind, placebo-controlled phase III trial. Diabetes Obes Metab. 2015;17(3): 309-312.

25. Kadowaki T, Kondo K. Efficacy and safety of teneligliptin added to glimepiride in Japanese patients with type 2 diabetes mellitus: a randomized, double-blind, placebo-controlled study with an open-label, long-term extension. Diabetes Obes Metab. 2014;16(5):418-425.

26. Kadowaki T, Kondo KJ. Efficacy and safety of teneligliptin in combination with pioglitazone in Japanese patients with type 2 diabetes mellitus. J Diabetes Investig. 2013;4(6):576-584.

27. Tanaka S, Suzuki K, Aoki C, et al. Add-on treatment with teneligliptin ameliorates glucose fluctuations and improves glycemic control index in Japanese patients with type 2 diabetes on insulin therapy. Diabetes Technol Ther. 2014;16(12):840-845.

28. [No authors listed]. Gliptins, exenatide, liraglutide: "intestinal obstruction". Prescrire Int. 2016;25(167):17.
29. Huml RA, Turner JR [webpage on the Internet]. The Current Regulatory Landscape for Cardiac \& Cardiovascular Safety Assessments: Part I. Available from: http://www.quintiles.com/ /media/library/experts/ the-current-regulatory-landscape-for-cardiac-and-cardiovascularsafety-assessments-part-i.pdf. Accessed April 08, 2016.

30. Heller S, Darpö B, Mitchell MI, et al. Considerations for assessing the potential effects of antidiabetes drugs on cardiac ventricular repolarization: a report from the Cardiac Safety Research Consortium. Am Heart J. 2015;170(1):23-35.

31. Fisman EZ, Tenenbaum A. Antidiabetic treatment with gliptins: focus on cardiovascular effects and outcomes. Cardiovasc Diabetol. 2015; 14(1):129.

32. Hashikata T, Yamaoka-Tojo M, Kakizaki R, et al. Teneligliptin improves left ventricular diastolic function and endothelial function in patients with diabetes. Heart Vessels. Epub 2015 Aug 13.

33. Morishita R, Nakagami H. Teneligliptin: expectations for its pleiotropic action. Expert Opin Pharmacother. 2015;16(3):417-426.

\section{Publish your work in this journal}

Diabetes, Metabolic Syndrome and Obesity: Targets and Therapy is an international, peer-reviewed open-access journal committed to the rapid publication of the latest laboratory and clinical findings in the fields of diabetes, metabolic syndrome and obesity research. Original research, review, case reports, hypothesis formation, expert opinion and commentaries are all considered for publication. The manuscript management system is completely online and includes a very quick and fair peer-review system, which is all easy to use. Visit http://www.dovepress.com/testimonials.php to read real quotes from published authors. 